\title{
Modeling an Individual and Group Decision on the Implementation of a Real Estate Development Project
}

\author{
Elena Romanova* \\ Moscow State University of Civil Engineering, Yaroslavskoe shosse, 26, Moscow, 129337, Russia
}

\begin{abstract}
The implementation of the real estate development project are accompanied many management decisions. These decisions can be made by one person or a project team. The article describes the advantages and disadvantages of individual and group decisions. The results of a comparative research of decision-making by one person and a group using computer decision support systems and without them. It is shown that using of automation tools facilitates decision making and increases confidence in its correctness. It has been experimentally proved that the individual solution is based on a smaller number of factors, is accepted more quickly and more satisfied by the person making the decision, in comparison with the group decision. Further the difficulties in implementing computer decision support systems in the work of a development company and acquired benefits are listed.
\end{abstract}

\section{Introduction}

Implementation of the real estate development project is accompanied by numerous decisions. It begins exactly with decision-making. This process on inclusion in a portfolio next project relies on the following procedures: the investment analysis of the considered construction projects; their ranging on indicators of efficiency investments; choice most profitable project; forecasting of profitability consider real-estate market development; medium-term and long-term planning of the projects portfolio and programs of works the development organization [1]. It is impossible to carry out these procedures without using of automation equipment.

If there is no automated system of supporting decision-making in organization, decisions have high variability. To stabilize and adapt a project to the changing, undefined conditions is possible only by operational administrative decisions [2]. It is necessary to consider a large number of unstructured information for them which extremely difficult for processing and analyzing.

To justify management decisions, build an effective system of relations and operational management, the developer needs not only unrestricted access to all information relating to the project being implemented, but also a system of tools, methods and models of data

\footnotetext{
* Corresponding author: romanova_e_v@mail.ru
} 
processing adapted for the project.The computer systems of supporting decision-making (SSDM) are examples of such tools [3].

As a rule, implementation of the real estate development project is enabled by project team. For effective work on the project at all stages of his realization is required a large number of various solutions. These decisions could make both one person (DM), and all team.

In social psychology there are a lot of researches devoted to analysis and comparison individual and group ways of decision-making [4]. The pros and cons of these decisions are revealed experimentally.

For the beginning, let's consider individual decision-making.

Advantages:

- efficiency. The one DM makes the decision much quicker than group. Decisionmaking in group takes much more time because of existence a number of views. Time is also required to the collection of participants.

- personal responsibility. The DM bears responsibility for his actions and solutions. In group there is nobody to make responsibility for the wrong decision.

- extent of focusing. One person is more focused on decision-making, than a group.

Disadvantages:

- search of the decision usually ends when the DM finds the alternative which answers to criterion "good enough". So the final solution represents a satisfying choice rather than an optimum one.

- individual decision-making has the essential psychological restrictions connected with personal characteristics and style of activity the DM.

And now let's consider group decision.

Advantages:

- the group owns more complete and various information in comparison with one person.

- the number of views, opinions and intuitions helps to estimate alternatives from the different sides and choose the best.

- at group decision-making the hidden talents and key competences of the organization's staff are open.

Disadvantages:

- some persons usually disagree with the final decision. Always remain dissatisfied people which in case of a failure will look for who is guilty.

- the group sometimes is made a compromise. Such decision is not always the best.

In general, individual decision-making saves time, money and energy as people accept fast and rather logical decisions. While group decision-making demands a lot of time, money and energy. However, one person won't take the interests of each member. The group usually considers the interests of all the members.

In this work is described the result of a comparative research about process of adoption individual and group decisions in the choice the development project on the real estate with using of specialized computer programs and without them.

\section{Methods}

In carrying out this research we used methods of the analysis scientific sources and software products, studying and synthesis accumulated experience of informatization and modeling about management of interaction participants in the investment and construction sphere in general and the development project on the real estate in particular. These methods allow defining problem area of a research, to describe and to prove the reached level in solution of a project task, to define the new sides and aspects in consideration a 
problem. Finally, all these methods give us an opportunity to go to the process of modeling more effective computer DSS by participants of the development project on the real estate.

Also during this research we used the method of modeling situations to decision-making, processing and analysis results of the observation.

36 students of a magistracy studying the program "Real Estate Development" took part in this research. They were divided into 4 subgroups. In two subgroups individual decisions were made and in others were group decisions. Respondents could choose in which mode they want to work - individually or in a group.

Stimulus material is the case. There are short characteristics of the real development company and the description of three real estate objects. More complete information about the company and objects you could found in the Internet. Examinees had to choose one of three objects which will be realized by the company as the development project.

In the first subgroup ( 3 persons) each participant of group solved a case independently, using only his analytical skills.

In the second subgroup ( 3 groups) participants solved a problem in groups of 5 people, also using analysis.

In the third subgroup participants had to use the computer program "Simba DSS" to find a solution for the task. The problem was solved individually ( 3 persons).

In the fourth subgroup ( 3 groups) individual opinions of 5 examinees were united and processed by a computer program "AdES - Analitic/Expert".

During an experiment were estimated quantity and quality of the factors accounted for decision-making, validity of the decision, confidence in the made decision, aspiration to normalize and structure information for its further processing, time of performance a task.

The "Simba DSS" [5] program is intended for individual work of the DM, the program "AdES - Analitic/Expert" [6] allows to process expert estimates.

\section{Results}

The case for analysis contained small volume of the most general information about the development company and real estate objects. Information about real estate objects wasn't identical: the location, cost, existence of infrastructure, social characteristics of the area, results of market researches, availability of documentation were, etc. were combined in different variations. Therefore, to conduct the qualitative comparative analysis of objects, using only initial information, was impossible. For the solving the problem, examinees were needed to obtain additional information. And for this purpose they could use the Internet.

During the individual work (the first and the third subgroups) examinees have selected for the analysis from 4 to 8 factors. It corresponds to the standard volume of random access memory and attention. The participants of the first subgroup, who's working without using of DSS, marked out bigger quantity of factors in the beginning, but during the analysis excluded some of them as insignificant or too difficult for processing. The examinees using DSS also reduced quantity of the analyzed factors in the course of work. But they have explained it with the fact that they couldn't present the obtained information in the form necessary for the automated processing. At the same time factors, insignificant for decisionmaking (having equal value for all objects), weren't excluded anymore after introduction them into program.

This fact shows that making the decision without using of DSS, the person feels heavier responsibility, commensurates the volume of information and his opportunities for its processing and consciously limits the analyzed information. At the same time, a significant part of the data may be lost. 
Using of DSS induces a person to shift part of efforts information processing on the computer and focus on preparatory work: selection and structuring information.

In the first case of the DM analyzes information from the point of the importance for decision-making. In the second case - he estimates an opportunity to provide this information in the form necessary for the automated processing.

Examinees of the first subgroup proved the made decision, listing as arguments everything (almost everything) of the selected factors. Examinees of the third subgroup reasoned the choice, relying only on 2-3 most significant factors. After decision-making other factors have been estimated as insignificant and have been excluded from the field of attention. It means that selection of significant factors happens not at the initial stage of the analysis, and after information processing.

During the group work examinees selected factors for the analysis collectively. An opportunity to divide work between participants of group has led to increase in number of factors which have been initially offered for decision-making. Final selection of factors for the analysis was similar to individual work. The second group working without DSS has excluded insignificant factors at the initial stage of work. The fourth group using the automated processing in work excluded factors only after the end of processing, at a stage of the argument their choice.

In general, at individual performance of a task examinees considered less factors than during the group work. It is connected with the variety of opinions noted above and aspiration each member of the group to make the contribution to the final decision.

Time to perform a task was also significantly differed. Students from the first subgroup have most quickly coped with work. On the second place was the third subgroup, then the fourth and second subgroups. Moreover, we will note that to the second and third subgroup has been allocated extra time for acquaintance with DSS. It was considered in the overall ranking of time. For removal of technical questions on work of DSS participants could use the help of the assistant. However, they had to enter information independently. The fact that development of the computer program has slowed down work of the DM at individual performance of a task and has accelerated it during the group work. In the second subgroup a considerable part of time was occupied by comparison of factors and coordination of opinions. The fourth subgroup hadn't spent time on it because data processing was made by the computer. This group only needed to agree or disagree with the offered. In our research all groups have agreed with conclusions.

The satisfaction of examinees with the made decision was separately estimated. The greatest satisfaction was shown by participants of the third subgroup. After research they have said that they initially assumed that the best object will be that which was chosen by DSS. The computer has only helped them to confirm their assumption. On the second place on confidence were representatives of the first subgroup. They have agreed that their choice not the best, perhaps, but in these conditions he is the most reasonable. Participants of the fourth subgroup are in the third place. Certain members of groups were dissatisfied with the final decision, but in general they have agreed with the calculations executed by the computer. They have noted that at individual performance of tasks they would carry out the analysis once again and would have added additional factors. The most unsatisfied persons from the developed decision were participants of the second subgroup. Most of them noted that the full-fledged group discussion hasn't turned out. Leadership in group was taken by one of participants, and his opinion was dominating. Other members of the group just lacked arguments and oratorical skills to argue their point of view.

Summary results on all estimated parameters are presented in table 1. 
Table 1. Results of the comparative analysis in work of subgroups.

\begin{tabular}{|c|c|c|c|c|}
\hline Factor & 1 subgroup & 2 subgroup & 3 subgroup & 4 subgroup \\
\hline $\begin{array}{c}\text { quantity of the } \\
\text { considered factors }\end{array}$ & $4-5$ & $5-9$ & $5-8$ & $7-11$ \\
\hline $\begin{array}{c}\text { quality of the } \\
\text { considered factors }\end{array}$ & $\begin{array}{c}\text { diverse, } \\
\text { significant }\end{array}$ & $\begin{array}{c}\text { diverse, } \\
\text { significant } \\
\text { and } \\
\text { insignificant }\end{array}$ & $\begin{array}{c}\text { diverse, } \\
\text { significant } \\
\text { and } \\
\text { insignificant }\end{array}$ & $\begin{array}{c}\text { diverse, } \\
\text { significant } \\
\text { and } \\
\text { insignificant }\end{array}$ \\
\hline $\begin{array}{c}\text { quantity of the } \\
\text { adduced } \\
\text { arguments in } \\
\text { protection of the } \\
\text { decision }\end{array}$ & $4-5$ & $8-9$ & $2-3$ & $4-5$ \\
\hline $\begin{array}{c}\text { rathoning and } \\
\text { structure of } \\
\text { information }\end{array}$ & low & low & high & high \\
\hline $\begin{array}{c}\text { time of } \\
\text { performance a } \\
\text { task }\end{array}$ & $60-80$ min & $150-180$ min & $90-120$ min & $120-135$ min \\
\hline $\begin{array}{c}\text { satisfaction with } \\
\text { result (from 0 to 5 } \\
\text { points) }\end{array}$ & 4,5 & 2,5 & 5 & 4 \\
\hline
\end{tabular}

\section{Discussions}

DSS is a set of procedures for data processing and the judgments helping manager with decision-making. It is based on using mathematical models. DSS doesn't give ready decisions, but helps to transform information into effective actions. Advantage of computer DSS consists in big speed and memory size [7]. Besides, modern DSS are able to adapt to the style of person's work who is making decisions, to reflect his style of thinking [8].

Practice of DSS introduction in the development companies has revealed a number of essential difficulties in its using. The first is the large volume of unstructured and uncoordinated data. During the developing and the choosing of the investment development project it is necessary to consider sources and financing terms; possible and preferable options of placement of the building; boundary technical and economic characteristics and indicators of an estimated object; special conditions of investment. For using available data in DSS we need to lead them to a general view, to normalize and structure, construct and interpret the indicators system of a state, efficiency or quality of the estimated parameter or an object. Transformation of data to the structured information is the most difficult task of automation [9].

The development project is created and implemented in real, occasionally unpredictably changing conditions. The effective solution will be based only on objective and most reliable data about control object. Such information is usually stored in operational databases. But these operational data are not suitable for the analysis purposes as for the analysis and decision-making the aggregated information is generally necessary. It can be received only in the certain specialized data store where there is an integration, updating and coordination of operational data from heterogeneous sources [10]. The shortcoming and at the same time competitive advantage of such storage consists in its self-sufficiency, closeness for others, external in relation to this company, users.

Another problem of implementation DSS in operation of the development company is insufficient possession of principals and specialists of the company information 
technologies. For overcoming this problem DSS developers aim to make the product the most clear for experts: use friendly, intuitively the clear interface, create pop-up explanations and hints, provide user training, issue detailed reference manuals and collections of examples, connect security features from unintentional and incorrect actions of the user.

The following problem is variety of solvable tasks which have different structure and contents. For introduction DSS in the organization the system has to be customized on different type of tasks and subject domains

The next problem is constantly increasing volume of the changing information. It results in complexity of orientation in irregular information and inadmissible loss part of important data. The good system has give to the user an opportunity of hierarchical data presentation, received estimates and conclusions, control of information which lost at each analysis stage. By methods of processing diverse data, the system has bring together diverse opinions that will provide their more careful control and assessment.

In large companies in preparation and decision-making the whole team usually participates. It is the group of experts which is responsible for this or that stage of process in supporting decision. This is the head on whom the problem of the final choice of the best option lays down. It is also a number of interested persons. Therefore, decision-making is followed at the same time by processes of the individual and group choice. In these cases, it is necessary to use group DSS. GDSS supports group of the users working on performance of the general task $[11,12]$. In a different way it is called Communication-Driven DSS. Communications-driven group decision support systems are best suited for virtual organizations that require a lot of technological support to foster communication and collaboration and get the work done.

A virtual organization is an association of physically and/or professionally detached individuals working together on the project. It doesn't have any physical existence but the Internet technology makes it look real.

The GDSS system is the perspective direction of DSS evolution [13]. In spite of the fact that evolution can demand considerable investments, organizational benefits of its introduction in the development company can be considerable and essential $[14,15]$.

\section{Conclusions}

All the ways of decision-making are within two extreme "poles" - individual solutions and group solutions. On different sites of this continuum changes the ratio measure of one-man management and collective nature in preparation and adoption of the administrative decision. There is an opinion that in general those decisions which justifications prepare jointly but are accepted individually are most effective [16]. The conducted research has shown that the individual decision is based on smaller quantity of factors, is accepted quicker and satisfies the DM more, in comparison with the group decision. However, individual decision-making has the essential psychological restrictions connected with features of the person making the decision. Ignorance and ignoring of these features is capable to lead the company serious problems. Among the main barriers and restrictions mark out haste; delay, emotional justifications of the decision; inability of the person of the accepting decision to recognize the mistakes; the self-confidence closing an opportunity to make using of positive experience and knowledge of other participants of the project [17]. Partially the automated DSS helps to reduce influence of these barriers. It doesn't make the decision independently, but gives the DM information for the analysis and correction of own opinion. Thus, introduction of the automated DSS in the development companies and their using for decision-making at different stages of implementation of the project is perspective direction of informatization and automation management process. 


\section{References}

1. Risk management in projection and construction - URL:http://riskgap.ru/aec/

2. V.I. Uspalenko, N.S. Leskovskaya, S. and prog. of transport. Bul. of the Dnipropetrovsk nat. U. of railway transport, 40, 226-230 (2012)

3. M. Mora, G. Phillips-Wren, F. Wang, The Routledge Companion to Risk, Crisis and Security in Business, 441-456 (Routledge, 2018)

4. A. Ambrus, B. Greiner, P. Pathak, Economics Working Papers, 0091 (2009)

5. SIMBA DSS - URL: http/www. simba.su /

6. A.N. Ogurcov, S. and P. J. Branch aspects of technical Sciences, 12, 15-18 (2011)

7. G. Daras - https://www.researchgate.net/publication/324217855

8. N. Conteh, J. of Technology Research - http://www.aabri.com/manuscripts/09193.pdf (2013)

9. V.V. Matveev, I.O. Melymko, GIAB (S.-T. J.), 2, 364-365 (2011)

10. R. H. Sprague, MIS Q., 4(4), 1-26 (1980)

11. Wall, J., M. Bertoni, T. Larsson, Norddesign conference proceedings, The Design Society (2018)

12. A.Yu. Yurin, G.S. Maltugueva, A.I. Pavlov, Software\&Systems, 2 (2011)

13. J. Wall, M. Bertoni, T. C. Larsson ICED, 4, 513-522 (2017)

14. J. N. D. Gupta, G. A. Forgionne, M. T. Mora, Intelligent decision-making support systems : foundations, applications and challenges (London . Springer, 2006)

15. G. Markovic, I. Pogarcic, S. Suman, Annals of DAAAM for 2012, 23 (1), 0737-0742 (2012)

16. I.P. Cherednichenko, N.V. Tel'nyh, Management psychology (Rostov-na-Donu: Feniks, 2004)

17. R.I. Mokshancev, Psychology of negotiations (M.-Novosibirsk, 2002) 